\title{
Propositions are not representational
}

\author{
Thomas D. Brown ${ }^{1}$ (1]
}

Received: 9 June 2020 / Accepted: 24 December 2020 / Published online: 9 January 2021

(c) The Author(s) 2021

\begin{abstract}
It is often presumed by those who use propositions in their theories that propositions are representational; that is, that propositions represent the world as being some way. This paper makes two claims against this presumption. First, it argues that it does not follow from the fact that propositions play the theoretical roles usually attributed to them that they are representational. This conclusion is reached by rebutting three arguments that can be made in support of the claim that propositions are representational. This paper then advances the further claim that propositions are not representational. It considers several ways to overcome the difficulties traditionally associated with this claim, particularly how to account for falsity.
\end{abstract}

Keywords Attitudes $\cdot$ Falsity $\cdot$ Meaning $\cdot$ Propositions $\cdot$ Representation $\cdot$ Truth

\section{Propositions and representation}

The view that propositions are representational-to be defined below, but which can be provisionally labelled Robust Propositional Representation (Robust PR) - is pervasive with theorists who make use of propositions. This paper advances both a stronger and a weaker claim against Robust PR. The stronger claim is that propositions are not entities that represent the world as being some way. Advancing this stronger claim will require some positive theorising about the nature of propositions. To fully establish this claim, it would need to be shown that some non-representational entity can play the roles usually attributed to propositions. However, a weaker claim-one that does not rely on any contentious claims regarding the nature of propositions - is also advanced: it does not follow from the fact that propositions play the theoretical roles usually attributed to them that Robust PR is true. The consequence of this claim is that the common presumption that propositions are representational requires further justification than is typically given.

Thomas D. Brown

t.brown4@liverpool.ac.uk

1 Department of Philosophy, University of Liverpool, Liverpool, UK 
These conclusions are reached as follows. After setting out the theoretical landscape in the remainder of Sect. 1, Sect. 2 then aims to refute two abductive arguments for Robust PR. These arguments are derived from propositions' roles as the objects of propositional attitudes and the meanings of sentences. ${ }^{1}$ It is concluded that the connection between attitudes and sentences, on the one hand, and the world that they represent, on the other, does not require representational propositions. Sect. 3 aims to refute the other main argument for Robust PR. This argument is derived from propositions' roles as the primary bearers of truth-values. It is proposed that propositions, as primary truth-value bearers, are not representational. In this respect propositions differ from derivative truth-value bearers (such as attitudes and sentences) which are representational. This part of the paper concludes with the claim that supporters of Robust PR cannot presume that propositions are representational because they play the theoretical roles usually attributed to them. Sect. 4 builds upon this conclusion to advance the stronger claim that propositions are not representational. It does so by outlining some strategies that might be utilised to respond to the problem posed by false propositions.

Before considering the arguments in favour of Robust PR we can set out three possible positions on whether propositions are representational. ${ }^{2}$ The predominant view that propositions are representational can be defined as follows:

Robust Propositional Representation (Robust PR): Propositions represent the world as being some way.

Robust PR claims that propositions are representational just as other representational entities such as propositional attitudes and declarative sentences are representational. This position is adopted by supporters of a diverse range of proposition theories including Hanks (2015), King (2007), Merricks (2015), and Soames (2010, 2014). This paper's weaker claim, mentioned above, is that Robust PR does not follow from the fact that propositions play the theoretical roles usually attributed to them.

The second possible position denies Robust PR's claim:

Eliminativist Propositional Representation (Eliminativist PR): Propositions do not represent the world as being some way.

Eliminativist PR denies that propositions are representational in any sense. Eliminativist PR does not entail complete eliminativism about propositions: it is compatible with holding that propositions are, for example, states of affairs or sets of possible worlds. This paper's stronger claim, advanced in Sect. 4, is that Eliminativist PR is true.

There is ostensibly another, weaker sense in which the theorist might claim that propositions are representational. Richard (2013, p. 705), for example, claims that

\footnotetext{
1 For simplicity, in this paper I am considering only declarative sentences.

2 Following Lorraine Juliano Keller's 'In Defense of Magic' presented to the Birkbeck Workshop on the Role of Content in Mind, Language and Metaphysics, London, 3 May 2018.
} 
propositions 'are representational in the minimal sense that they are true or false.' This third position is introduced for completeness:

Deflationary Propositional Representation (Deflationary PR): Propositions are representational entities in the minimal sense that they have truth-values. Propositions are not, strictly speaking, about anything.

For the remainder of this paper, I will set aside Deflationary PR. The question of whether something can be a representation but not 'about anything' is tangential to the disagreement between Robust PR and Eliminativist PR on which this paper is focused.

The reason that Robust PR is the predominant position on propositional representation is related to the theoretical roles that propositions are thought to play. Against this, Sects. 2 and 3 of this paper argue that Eliminativist PR is equally compatible with holding that propositions play these theoretical roles.

Not all theorists agree on the theoretical roles that propositions play but there is, in the recent literature at least, an overwhelming consensus on three primary roles ${ }^{3}$ :

MEANING: For any declarative sentence, uttered in a given context, its meaning is, in that context, a proposition.

ATTITUDE: Propositions are the objects, or contents, of at least some attitudes (for example, belief-that) and these attitudes are characterised by an agent standing in a particular relation to a proposition.

TRUTH: Propositions are the primary bearers of truth-values.

These three theoretical roles correspond to three characteristic arguments for Robust PR which are presented by Speaks (2014, p. 215) as follows:

(1) Mental states, such as beliefs, are about things, and this fact about mental states is best explained in terms of the representational properties of the propositions which are their contents.

(2) Sentences are about things, and this fact about sentences is best explained in terms of the representational properties of the propositions which (relative to contexts) they express.

(3) Propositions are the sorts of things that can be true or false, and this shows that they must have representational properties.

These arguments express the underlying reasoning behind the common presumption that Robust PR is true. In arguments (1) and (2) the Robust PR theorist explains how mental states and sentences can represent the world as being some way via the representational properties of propositions. Challenging the claim that Robust PR is the best explanation for how mental states and sentences can represent the world

\footnotetext{
3 For a small sample of this consensus, see: Grzankowski and Buchanan (2019, pp. 3160-3161), Keller (2017, pp. 930-931), King (2007, pp. 1-2, 2014, pp. 5-6), Merricks (2015, pp. 193-194), Soames (2010, pp. 2-3), Speaks (2014, p. 215). Both Hanks (2015) and Richard (2013) reject the view that propositions are the primary truth-value-bearing entities but, as Hanks (ibid., p. 3) notes, this is a dissenting opinion.
} 
as being some way is the topic of Sect. 2. Argument (3) contends that the only sorts of things which can be true or false are representational entities. Challenging this claim is the topic Sect. 3. If these three arguments are refuted, and therefore also the reasoning behind commitment to Robust PR, then supporters of Robust PR will be required to offer further, independent justification for their claim that propositions are representational.

\section{Attitudes and sentences}

In arguments (1) and (2) Robust PR is inferred as the best explanation for how propositions play the roles of ATTITUDE and MEANING. Focusing on argument (1) and propositional attitudes first, let us be clear about what needs to be explained. Attitudes, such as belief, can represent the world as being some way. Robust PR theorists can explain how attitudes can represent by claiming that the contents of the attitudes, propositions, themselves represent. The representational properties of attitudes are inherited from the representational properties of propositions. Eliminativist PR, in contrast, cannot resort to the representational properties of propositions. The challenge for Eliminativist PR is to provide an explanation of how attitudes can represent.

First, note that Robust PR merely pushes the explanation that was originally sought back a stage in the project of explaining propositional attitudes. The Robust PR theorist replaces the mystery of representational attitudes with the mystery of representational propositions. The Robust PR theorist usually then gives an account of how propositions are representational. By providing a theory of propositions they attempt to solve this newly contrived mystery.

This relocation of the explanatory burden can be clearly seen when examples are considered. Take cognitive proposition theorists such as Soames $(2010,2014)$ or Hanks (2015). Cognitive proposition theories utilise cognitive representational ability (in particular, acts of predication) to 'endow [propositions] with representational meaning or content' (Soames 2010, p. 31). Propositions, for Soames and Hanks, are cognitive event types: that is, they are abstract types whose tokens are the concrete representational actions of cognitive agents.

But this strategy amounts to a reversal of the of the explanatory direction, rather than a genuine explanation of representation. Indeed, Hanks (2015, p. 4) acknowledges this reversal when he states that 'propositions inherit their representational features from these [representational] acts'. If token acts of predication are intrinsically representational (in that, by predicating a property of an object we represent the world as being some way) then this commits the cognitive theorist to mental acts that are intrinsically representational. But, if one is happy to endorse the claim that mental acts are intrinsically representational, there is no need to defer to Robust PR to explain how propositional attitudes represent and argument (1) is undermined.

Consider another example of the relocation of the burden of explaining representational attitudes. Other theorists respond to Robust PR's contrived mystery of how propositions represent with primitive proposition theories. Merricks (2015, p. 195), 
for example, claims that 'there is no explanation of how a proposition manages to represent things as being a certain way.'

Like cognitive proposition theories, primitive proposition theories also gain no explanatory benefit from commitment to Robust PR. One objection to primitive theories, raised by King (2009, p. 260), is that 'taking any kind of representation as primitive is a paradigm example of misplacing one's primitives'. But, even if we accept that the ability to represent may be a primitive property, locating it in propositions has no theoretical benefit over locating it in the representational attitudes we are aiming to explain in the first place.

The point of the above two examples generalises. If the Robust PR theorist explains how propositions represent, then they are obligated also to explain why this explanation cannot be provided at the level of representational attitudes. Without this additional explanation, the representational propositions of Robust PR appear to be an unnecessary commitment.

To reiterate this point, once theories of propositions that incorporate Robust PR are fully explored it becomes clear that any explanatory power gained by endorsing Robust PR is gained illegitimately. A new mystery emerges when Robust PR is used to explain how attitudes represent and, more importantly, it is not clear why the proposed solutions to the new mystery are not better suited to the original problem of explaining how attitudes can represent. Taking the cognitive and primitive theories of representation noted above as characteristic examples, there is no principled reason to apply the explanation of representational ability provided by these theories at the level of propositions rather than at the level of representational attitudes that required explaining in the first place.

To justify the weaker claim of this paper, it needs to be shown that the fact that propositions play the role of ATTITUDE is compatible with holding a position that is not Robust PR. To that end, we are in a position begin to sketch an account of propositional attitudes from what remains if we abandon Robust PR in favour of Eliminativist PR.

Note that there are two parts to the standard picture of propositional attitudes that we have been considering: (1) propositions, and (2) attitudinal relations to propositions. As Grzankowski and Buchanan (2019, p. 3168) emphasise, the fact that propositions can play the role of ATTITUDE depends 'not only on the nature of [propositions] but also on the nature of the relation we bear to them'.

Speaks $(2014$, p. 220) begins to develop the same point by suggesting that the explanatory burden of representation can be relocated from propositions to certain relations between things (in this case the mental acts of belief, for example) and propositions. The primary task for propositions, in playing the role of the objects of attitudes, is merely to track what it is that particular attitudes are representing. There is no reason to think that Robust PR must be true for propositions to allow us to do this sort of theoretical tracking. Eliminativist PR is equally able to support an account of propositions in which their role as the objects of attitudes is tracking what it is that a particular attitude is representing.

Jones (2019) develops one way of understanding the propositional side of this attitudinal relation. The part of Jones' proposal relevant to the current discussion is his claim that propositions are the worldly relata of particular cognitive relations. 
Jones claims that 'propositions are familiar entities [...] that all theorists implicitly recognize, for example: Tibbles is hungry, the sun is shining' (ibid., p.172). It is clear that, on Jones' account, there is no need to claim that propositions are representational in order to account for their role as the contents of propositional attitudes. ${ }^{4}$

The other explanation sought is related to the role of MEANING: how is it that sentences can represent the world as being some way? Argument (2) works in precisely the same way as argument (1) did for ATTITUDE: the truth of Robust PR is inferred from the requirement for an explanation of how sentences are able to represent.

It suffices here, where we are focused on propositions, to point out that the above strategy used to object to argument (1) generalises. Just as the burden should be placed on the relation between an attitude and a proposition, the burden here should be placed on the relation between a sentence and its meaning. This makes the commitment to Robust PR redundant when considered for the sole purpose of explaining how sentences can represent. Robust PR shifts, rather than undertakes, the task of explaining how sentences represent.

A fully developed theory of meaning will take on this explanatory task and account for how sentences can represent the world via their relation to a proposition. For example, this might take the form of specifying the sentence formation rules of a natural language with complex sentences composed out of meaningful sub-sentential parts. However, within the restricted scope of a theory of propositions, we are interested primarily in the propositional side of the relation. To reiterate the claim made earlier regarding representational attitudes, the role that propositions play as the meanings of sentences is merely to track what it is that particular sentences are representing. Eliminativist PR is equally adequate for this task and, therefore, it does not follow from the fact that propositions play this role that Robust PR is true.

It may be objected that Eliminativist PR sacrifices a degree of explanatory power: whilst Robust PR offers an explanation of how both attitudes and sentences represent from the prior representational properties of propositions, Eliminativist PR must offer a different explanation in each case. This sacrifice of generality, however, is supported by a very plausible picture of representation as the kind of phenomenon that requires an explanation which depends on both the vehicle of the representation (in our case, either a mental state or a sentence) and its particular relation to what is represented.

Once the burden of explaining how attitudes and sentences can represent has been shifted from propositions there is no longer any reason to endorse Robust PR just because propositions play the roles of ATTITUDE and MEANING. Furthermore, an Eliminativist PR theory is equally able to explain how propositions play the roles of ATTITUDE and MEANING. Propositions play these roles by allowing us to track what it is that propositional attitudes and declarative sentences are representing.

\footnotetext{
4 Jones' further claim is that propositions are not objects and that, therefore, there is no question of their 'deep metaphysical nature' (2019, p. 173). If Jones' arguments for this claim are successful, then the falsity of Robust PR (and the alternative positions alike) is a mere corollary.
} 


\section{Truth-value bearers}

Once the requirement that propositions are representational has been removed from the perspective of our semantic and propositional-attitude theories, we need to look elsewhere for reasons to endorse Robust PR. The third argument for Robust PR that was stated in Sect. 1 relates to propositions' roles as bearers of truth-values:

(3) Propositions are the sorts of things that can be true or false, and this shows that they must have representational properties. (Speaks, 2014, p. 215).

This reasoning has been influential. Jubien (2001, p. 50), for example, expresses the apparent implausibility of the alternative:

Propositions represent the world as being one way or another. If they didn't represent in this way, it would be utterly implausible to view them as the ultimate bearers of truth values.

Jubien's claim is that if propositions were not representational, then there would be no way that propositions could play the role TRUTH that is usually attributed to them. There is a common assumption that propositions, if they are to be not just the primary or 'ultimate' truth-value bearers but any sort of truth-value bearers at all, must represent the world as being some way. This assumption forms the basis of argument (3) for Robust PR.

Underlying this assumption is an adherence to a theory of truth which necessarily ties truth-value-bearing to representing. The connection between truth-value-bearing and representing is, loosely speaking, a hangover from traditional correspondence theories of truth which adhere to the intuition that truth-value bearers 'are true when they correspond to reality' (Lynch, 2009, p. 21). It is a natural step from this intuition to the assumption that the correspondence relation is representational: truth-value bearers represent the reality to which they correspond.

One option available to the Eliminativist PR theorist who is swayed by the conclusion of the previous section is to accept this traditional understanding of truthvalue-bearing and claim that propositions are not truth-value bearers. Whilst I do not wish to discount this as a live possibility, denying that propositions are truth-value bearers would be a substantial cost for many theorists who make use of propositions. Consider why a theorist might want propositions to be primary truth-value bearers. One reason is to account for the truth-value-link between synonymous sentences. We seem to be owed an explanation of why the truth-value of two sentences such as (1) 'Snow is white' and (2) 'La neige est blanche' are linked such that the truthvalue of (1) changes iff the truth-value of (2) does also. If both sentences inherit their truth-value from the same proposition, then this explains the link. If propositions do not bear truth-values, however, then this explanation is unavailable. To allow for the possibility of this explanation I will presume, along with the consensus mentioned in Sect. 1, that propositions are truth-value bearers.

An alternative Eliminativist PR strategy would be to endorse a theory of truth in which truth-value-bearing does not consist in a representational correspondence to the world. If the role TRUTH can be shown to be compatible with an account 
of propositional truth that supports Eliminativist PR, then argument (3) would be undermined. The weaker claim of this paper, that it does not follow from the fact that propositions play the three theoretical roles considered that Robust PR is true, would therefore be justified.

One possible alternative theory of truth claims that the relation between the world and propositions is not correspondence but identity. To take one such identity theory, Dodd (2000, p.3) characterises his position specifically in terms of a dissatisfaction with the core truth-making principle that he takes to be shared by all correspondence theories ${ }^{5}$ :

(TM) For $\langle p>$ to be true, there must exist at least one entity, distinct from $\langle p\rangle$, whose existence entails that $\langle p\rangle$ is true.

Dodd's version of identity theory claims that true propositions do not correspond to, but are identical with, facts. The rejection of (TM) and the subsequent adoption of identity theory is one way to undermine argument (3) for Robust PR. The identity theorist's claim that true propositions are facts severs the connection between being a truth-value bearer and representing the world.

However, it is possible to qualify Dodd's rejection of (TM) and to make a concession towards the correspondence theorist's proposed truism that truth consists in some correspondence to reality. The theory to be outlined avoids the problem of having to reject the truism and still undermines argument (3). We can retain some version of the correspondence theorist's truism if we adopt a position between the extremes of correspondence and identity theories. This middle ground is to be found in the distinction between primary and derivative truth-value bearers, so more must first be said about this distinction.

Propositions are thought to have priority over, for example, sentences when it comes to bearing a truth-value because sentences only have a truth-value if they express a proposition. Meaningless sentences (those that do not express a proposition) are neither true nor false. We say then that a sentence derives its truth-value from the proposition that it expresses. Whereas propositions are primary truth-value bearers, sentences have a truth-value only derivatively.

This distinction between primary and derivative truth-value bearers suggests the possibility of different kinds of truth operating at different levels of the semantic hierarchy. A split-level theory of truth which accounts for the primary-derivative distinction can accommodate both the correspondence theorist's truism and the Eliminativist PR theorist's worries regarding the representational correspondence relation between propositions and the world.

The principle underlying such a split-level theory is suggested by Speaks, who claims that propositions, despite bearing truth-values, are not representational. Regarding the proposed truism that truth must be accuracy in representation, Speaks (2014, p. 221) states that:

\footnotetext{
${ }^{5}$ Dodd follows the convention of using ' $\langle p\rangle$ ' for 'the proposition that $p$ ' (ibid., p.15 n. 3).
} 
On my view, it is a platitude that a sentence is true iff it represents the world as being some way, and the world is that way [...] But no such claim holds about the truth of propositions.

On such a view, there is a distinction between the notions of truth that are applicable at the primary and derivative levels.

One might object that there seems to be a univocal notion of truth which we ordinarily apply to both sentences and that-clauses which signify propositions. This is a point of fact to which any theory of truth owes an explanation: what is the notion of truth that applies to different kinds of entities (both propositions and sentences)? A split-level theory, however, is in a strong position to provide this explanation. Far from being a mysteriously univocal notion that is applicable to different kinds of entity, a split-level theory can point to a substantive difference in the notions applicable to propositions and sentences. The word 'truth', on this account, is polysemic. There is still a factual connection between the distinct notions of truth applicable to the different kinds of entity, but this connection is itself elucidated by the connection between primary and derivative truth-bearers.

This position is also suggested in outline by Gaskin $(2016, \S 3)$ as a way one might split a theory of truth so that one could hold 'an identity theory of truth at the level of Thought or proposition (or both) with a correspondence theory at the level of language'. This position charts a course between the disadvantages of both correspondence and identity theories. Its advantage is in retaining the explanatory benefits of propositions as primary bearers of truth-values, without abandoning the correspondence theorist's intuition that, for example, sentences are true or false due to their accuracy in representation.

This position adheres to the identity theorist's concept of truth at the level of propositions. This truth is primitive in the sense that not a lot can be informatively said about it: the truth or falsity of a proposition is 'a simple and unanalysable property' (Gaskin 2016, §5.6). The crucial point is that truth, for propositions, cannot be analysed as a relation to a further worldly entity: (TM) does not apply.

This concept of truth at the level of propositions suggests a problem, identified by Pickel (2019, p. 1149): 'why does the truth-value of a proposition co-vary with what's happening in the world at large?' In other words, how can propositions (as truth-value bearers) have truth-conditions? On this point, the split-level theory of truth must side against those, such as Pickel (ibid.) and Speaks (2014), who claim that propositions have truth-conditions. The identity theorist's notion of truth leaves no space for such co-variation between propositions and the world. Propositions themselves are the worldly truth-conditions for representational entities.

Here then, this position agrees with Trueman (2018), who claims that propositions do not themselves have propositional content. However, Trueman (ibid., p. 1818) also endorses the claim, discussed above, that propositions 'are not the sort of things that can be true or false'. I am happy to accommodate the alternative claim, that propositions are truth-value bearers, within a split-level theory of truth so long as it is recognised that this truth-value is primitive. If we wish to retain the claim 
that propositions are truth-value bearers, then there can be no general explanation of what makes a proposition true or false. ${ }^{6}$

Returning to the primary-derivative distinction, a different account of truth can be given at the level of sentences or propositional attitudes. All derivatively truthvalue-bearing entities have their truth-value because of a relation to a primitively truth-value-bearing proposition. However this might be fully spelt out, there is a commitment to a modified, derivative truth-making principle:

(DTM) For a derivative truth-value bearer $\mathrm{S}$ to be true/false, there must exist at least one primitive truth-value bearer, distinct from $S$, whose truth-value entails that $\mathrm{S}$ is true/false.

This principle merely makes explicit what it means to be a derivative truth-value bearer.

This split-level theory of truth severs the connection between representation and truth at the level of the proposition. Therefore, it does not require commitment to Robust PR. Like the identity theory of truth, this split-level theory is compatible with Eliminativist PR but, unlike the identity theory, this split-level theory can accommodate the plausible truism that sentences, for example, are true when they accurately represent reality.

That an identity theory of truth, or a more plausible split-level theory, is tenable establishes the claim that propositions do not need be representational to play the role of primary truth-value bearers. On either account, being the bearer of a truthvalue is not necessarily tied to the ability to represent the world as being some way. Consequently, the fact that propositions play the role of primary truth-value bearers does not entail Robust PR and argument (3) for Robust PR is undermined.

This paper's weaker claim is therefore established. Proponents of Robust PR cannot merely rely on a tacit assumption that propositions must be representational because they are the objects of propositional attitudes, the meanings of sentences, and the bearers of truth-values. To reiterate the conclusion of Sect. 2, the proponent of Robust PR must provide either: (1) a reason why their explanation of propositional representation cannot be applied to the representational attitudes and sentences that require an explanation in the first place; or (2) an independent reason why propositions must be representational in order to play the roles of ATTITUDE and MEANING. This section has removed one of those independent reasons. If the proponent of Robust PR wishes to claim that the role of TRUTH is the reason that propositions are representational then they must be explicit about their theory of truth which claims a necessary connection between truth-value-bearing and representing. Without such a theory of truth, the Eliminativist PR theorist is equally able to claim that propositions play the three theoretical roles typically attributed to them, whilst also claiming that propositions are not representational.

\footnotetext{
${ }^{6}$ Pickel (2019, p. 1432 n. 12) makes a concession towards identity theory but leaves the relation between it and his own proposal unexplored. Trueman (2018, p. 1819), however, does make space for a kind identity theory of truth within his own 'Prenective view' of propositions.
} 


\section{The stronger claim}

The arguments thus far have been in service of the weaker claim of this paper: it does not follow from the fact that propositions play the theoretical roles usually attributed to them that Robust PR is true. If theorists who make use of propositions wish to claim that Robust PR is true, then further justification for the claim is required. Without further justification, Robust PR is an idle theoretical commitment that merely shifts the burden of explanation from representational attitudes and sentences to representational propositions.

The stronger claim of this paper is that Eliminativist PR is the correct alternative to Robust PR and the remainder of the paper advances this claim. In particular, the aim of this concluding section is to set out several possible strategies to overcome a traditional hurdle that Eliminativist PR theories struggle to overcome. This requires some positive theorising about propositions and what sort of entities they must be in order to play the roles that are usually attributed to them.

We can begin by considering one kind of Eliminativist PR theory that posits a notably direct connection between representational attitudes and sentences on the one hand, and the world which they represent on the other. An example of such a theory was held by Russell at one point in the first decade of the $20^{\text {th }}$ Century. ${ }^{7}$ Russell (1906, p. 48) claims that propositions are 'objectives' or what we might now call states of affairs: that is, propositions are ways the world could be. True propositions are obtaining states of affairs (which Russell calls facts) or, put another way, ways the world is. False propositions, on this view, are non-obtaining states of affairs. Russell (1918, p. 55) later drew attention to a potential problem with this kind of Eliminativist PR theory and declared that:

...it does not seem to me very plausible to say that in addition to facts there are also these curious shadowy things going about such as "That today is Wednesday" when in fact it is Tuesday.

This is the problem of falsity. ${ }^{8}$ In this form, the problem is to explicate the nature of false propositions qua non-obtaining states of affairs. This is a problem particularly for Eliminativist PR because we want to know what sort of thing the meaning of a false sentence or the object of a false belief is. Whereas a Robust PR theorist can say that a false proposition is merely a representation of a way the world isn't, this type of Eliminativist PR theory says that the meaning of a false sentence or the object of a false belief is actually a way the world isn't. Russell's objection is that

\footnotetext{
7 Jones (2019) is a more recent example of a theory of propositions which holds a notably direct connection between the world and, what I have been calling, representational attitudes. Jones rejects the view that the contents of these attitudes are objects and, to that end, rejects the metaphysical questions about their nature that I am considering here.

${ }^{8}$ Russell (1904, p. 523) initially put the problem another way: 'it seems to remain that, when a proposition is false, something does not subsist which would subsist if the proposition were true'. Here Russell focuses the ontological problem of falsity, but he then goes on to entangle this with the difficulties entailed by so-called 'negative facts'. The problem of negative facts (or true negative propositions) is separate and adjacent to the problem of falsity on which I focus here.
} 
although we may be quite happy with the idea of a true proposition as a fact, or way the world is, the idea of an entity that is 'a way the world isn't' seems dubious. Russell's abandonment of propositions generally is rooted in this distrust of false propositions, which are variously called fictions, objective non-facts or, in more modern terminology, non-obtaining states of affairs. How can Eliminativist PR explain falsity if it cannot explicate false propositions?

Now despite the perceived force of Russell's objection to non-obtaining states of affairs, it amounts, here at least, to little more than an incredulous stare. One option available to the Eliminativist PR theorist is to bite the bullet on this point and accept false propositions (non-obtaining states of affairs) alongside true propositions (obtaining states of affairs) as full-blooded entities in their ontology. A full discussion of this metaontological point is outside the scope of this paper but we can note that there are methodological reasons a theorist might be led to accepting nonobtaining states of affairs into their ontology. Gaskin (2020, p. 165), for example, proposes that the existence of non-obtaining states of affairs is guaranteed by the existence of meaningful false sentences, for which false propositions are referents.

Gaskin's response to the problem of falsity adheres strictly to a more general methodological principle, which is also followed and concisely stated by Dodd (2000, p. 162):

Truth and falsehood must receive a uniform treatment [...] true propositions and false propositions must be of the same ontological category.

This is a constraining principle for Eliminativist PR theorists because it requires that falsity be explicated in exactly the same way as truth. The principle states that an adequate theory of propositions must be symmetric: true and false propositions must be ontologically on a par. This principle is often tacitly accepted but is not often explicitly justified. Russell, in his 1913 Theory of Knowledge manuscript Russell (1984, p. 109), does propose an argument for this symmetry principle:

It is obvious that what we call believing or understanding a proposition is a fact of the same logical form whether the proposition is true or whether it is false; for if this were not so, there would be an intrinsic difference between true and false beliefs, and mere attention to the mental fact would be capable of showing whether the belief was true or whether it was false. This, however, is unfortunately not the case. We must therefore say that, in the sense in which propositions are involved in believing and in propositional understanding, there is no difference, as regards reality, between true and false propositions.

Here, Russell employs a reductio argument against the view that the objects of true and false beliefs differ in an ontological sense. The argument claims that if true and false propositions differed 'as regards reality' then the logical forms of true and false 
beliefs would differ. ${ }^{9}$ Furthermore, we would be able to detect this difference in logical form by inspecting the 'mental fact'. Reformulated, the argument states:

(P1) If true and false beliefs had different logical forms, then it would be possible to distinguish which of our beliefs are true and which are false by attention to the mental fact.

(P2) It is not possible to distinguish which of our beliefs are true and which are false by attention to the mental fact.

(C) It is not the case that true and false beliefs have different logical forms (from $\mathrm{P} 1$ and P2)

A corollary of the conclusion, according to Russell, is that true and false propositions do not differ 'as regards reality'. The argument is valid and (P2) is true. ${ }^{10}$ Therefore, the argument can only be objected to by denying (P1).

In Russell's case, his own view of propositions entails that (P1) is false (Candlish 2007, p. 59). On Russell's account (at this stage in the development of his thought), propositions are states of affairs consisting of arrangements of worldly objects. To find out whether a particular state of affairs obtains or not requires inspection of the world: exactly how we do distinguish truths from falsehoods. This point generalises to any conception of propositions as worldly entities. Our beliefs, for example, represent the world as being some way and examination of these representations alone cannot tell us whether the world actually is that way.

Where does this leave us regarding our discussion of Eliminativist PR? In trying to understand how an Eliminativist PR theorist might explain falsity, note that Russell's argument does not establish that the logical forms of true and false beliefs cannot differ. If we accept the worldly conception of propositions, then there is still the possibility that the logical forms of true and false beliefs differ. This conclusion should not be surprising. Russell's own analysis of the logical form of definite descriptions provides an example of how the logical form of a linguistic expression is often disguised by its surface grammar. It is plausible that, similarly, the logical form of a belief is similarly disguised.

Russell is therefore not entitled to his conclusion, nor the corollary that true and false propositions do not differ 'as regards reality'. Without an argument in its favour, the principle which demands a symmetric theory of propositions is inadequately justified. The Eliminativist PR theorist may reject the principle to endorse a new strategy for explaining falsity. Rejecting the symmetry principle

\footnotetext{
9 Interestingly, Moore (1899, p. 180) differs from Russell on this conclusion. Moore claims that the different possible relations between the (worldly, non-psychological) concepts which constitute propositions determine whether a proposition is true or false. In this sense, the logical form of a proposition differs depending on its truth-value. The different relations that determine the different logical forms remain inexplicable for Moore, but the difference can be 'immediately recognised'. Thanks to an anonymous referee for pointing this out.

10 Strictly speaking, (P2) is not true in every case. Certain beliefs' truth-values can be known by attention to the mental fact (for example, beliefs whose objects are logical contradictions). In most cases, however, we cannot merely examine the mental fact to discover a belief's truth-value.
} 
allows the theorist to consider an asymmetric theory of propositions: a theory in which the answer to the question 'what are propositions?' differs, in an important ontological sense, between true and false propositions.

What are the benefits of endorsing an asymmetric theory and how might it support Eliminativist PR? One benefit is the ability to respond to the problem of falsity that was introduced above. An asymmetric theory provides a foundation for a more satisfying account of non-obtaining states of affairs. Some of the mystery implied in Russell's description of non-obtaining states of affairs, quoted above, as 'curious shadowy things' is dispelled if we can endorse a suitable ontological disparity with obtaining states of affairs.

One way to do this is to be explicit about the relation between the notions of obtainment and existence. Following Russell, it has commonly been assumed that non-obtaining states of affairs must be treated like obtaining states of affairs in regard to their existence. That is, existence is taken as the primitive ontological notion; whether a state of affairs obtains or not is secondary to the question of its existence. However, this conflicts with the ordinary understanding of obtainment as an existence predicate which applies particularly to states (or what Moltmann (2020, §6) calls 'condition-like objects'). If no explicit account can be given of how obtainment differs from existence, then we are left in a situation in which the distinction between obtainment and existence collapses. Following this collapse, false propositions, as non-obtaining states of affairs, are non-existent entities. Any attempt to endorse this position inherits difficulties similar to those raised by so-called non-referring, descriptive or fictional names.

An alternative Eliminativist PR and asymmetric theory might treat nonobtaining states of affairs as existent but ontologically derivative of prior obtaining states of affairs. The ontological disparity in this kind of asymmetric theory would be found, not in an existence/non-existence distinction but, in the notion of ontological dependence. If Russell's 'shadowy things' can be explained in this way, much of their mystery vanishes.

Both symmetric and asymmetric theories provide avenues that the Eliminativist PR theorist may take in response to the problem of falsity. Consequently, it is no objection to Eliminativist PR to claim that propositions must be representational in order to account for falsity. Furthermore, it is the direct connection between, for example, attitudes and the world that is secured by this kind of Eliminativist PR theory that makes it the most plausible position on whether or not propositions are representational.

Acknowledgements Thanks to Lorraine Juliano Keller for permission to cite the conference paper 'In Defense of Magic'. For their support and advice throughout the writing of this paper, special thanks to Richard Gaskin and Stephen McLeod. I would also like to thank the work-in-progress group at the University of Liverpool Philosophy department and two anonymous referees for their helpful comments and suggestions.

Funding This research was supported by funding from the Arts and Humanities Research Council. 


\section{Compliance with ethical standards}

Conflicts of interest The author declares that they have no conflicts of interest.

Open Access This article is licensed under a Creative Commons Attribution 4.0 International License, which permits use, sharing, adaptation, distribution and reproduction in any medium or format, as long as you give appropriate credit to the original author(s) and the source, provide a link to the Creative Commons licence, and indicate if changes were made. The images or other third party material in this article are included in the article's Creative Commons licence, unless indicated otherwise in a credit line to the material. If material is not included in the article's Creative Commons licence and your intended use is not permitted by statutory regulation or exceeds the permitted use, you will need to obtain permission directly from the copyright holder. To view a copy of this licence, visit http://creativecommons.org/licen ses/by/4.0/.

\section{References}

Candlish, S. (2007). The Russell/Bradley Dispute and its Significance for Twentieth Century Philosophy. Houndmills: Palgrave Macmillan.

Dodd, J. (2000). An Identity Theory of Truth. New York: Palgrave Macmillan.

Gaskin, R. (2015). The Identity Theory of Truth. In Zalta, E. N. (Ed.), The Stanford Encyclopedia of Philosophy. (2016) https://plato.stanford.edu/archives/win2016/entries/truth-identity/.

Gaskin, R. (2020). Language and World: A Defence of Linguistic Idealism. Abingdon: Routledge.

Grzankowski, A., \& Buchanan, R. (2019). Propositions on the cheap. Philosophical Studies, 176(12), 3159-3178. https://doi.org/10.1007/s11098-018-1168-6.

Hanks, P. (2015). Propositional Content. Oxford: Oxford University Press.

Jones, N. K. (2019). Propositions and cognitive relations. Proceedings of the Aristotelian Society, 119(2), 157-178. https://doi.org/10.1093/arisoc/aoz013.

Jubien, M. (2001). Propositions and the objects of thought. Philosophical Studies, 104(1), 47-62. https:// doi.org/10.1023/A:1010361210072.

Keller, L. J. (2017). Against naturalized cognitive propositions. Erkenntnis, 82(4), 929-946. https://doi. org/10.1007/s10670-016-9851-5.

King, J. C. (2007). The Nature and Structure of Content. Oxford: Oxford University Press.

King, J. C. (2009). Questions of unity. Proceedings of the Aristotelian Society, 109(1-3), 257-277. https ://doi.org/10.1111/j.1467-9264.2009.00267.x.

King, J. C. (2014). What Role do Propositions Play in our Theories? In King, J. C., Soames, S., \& Speaks, J. (2014), pp. 5-8.

King, J. C., Soames, S., \& Speaks, J. (2014). New Thinking about Propositions. Oxford: Oxford University Press.

Lynch, M. P. (2009). Truth as One and Many. Oxford: Oxford University Press.

Merricks, T. (2015). Propositions. Oxford: Oxford University Press.

Moltmann, F. (2020). Existence predicates. Synthese, 197(1), 311-335. https://doi.org/10.1007/s1122 9-018-1847-z.

Moore, G. E. (1899). The nature of judgement. Mind, New Series, 8(30), 176-193. https://doi. org/10.1093/mind/VIII.2.176.

Pickel, B. (2019). Unity through truth. Synthese, 196(4), 1425-1452. https://doi.org/10.1007/s1122 9-016-1279-6.

Richard, M. (2013). What are propositions? Canadian Journal of Philosophy, 43(5-6), 702-719. https:// doi.org/10.1080/00455091.2013.870738.

Russell, B. (1904). Meinong's theory of complexes and assumptions (III). Mind, 13(52), 509-524. https:// doi.org/10.1093/mind/XIII.1.509.

Russell, B. (1906). On the nature of truth. Proceedings of the Aristotelian Society, 7, 28-49. https://doi. org/10.1093/aristotelian/7.1.28.

Russell, B. (1918). The Philosophy of Logical Atomism. Abingdon: Routledge.

Russell, B. (1984). Theory of Knowledge: The 1913 Manuscript. Abingdon: Routledge.

Soames, S. (2010). What Is Meaning? Princeton: Princeton University Press. 
Soames, S. (2014). Cognitive Propositions. In King, J. C., Soames, S., and Speaks, J. (2014), pp. 91-124. Speaks, J. (2014). Representation and Structure in the Theory of Propositions. In King, J. C., Soames, S., \& Speaks, J. (2014), pp. 215-225.

Trueman, R. (2018). The Prenective View of propositional content. Synthese, 195(4), 1799-1825. https:// doi.org/10.1007/s11229-016-1309-4. 